\title{
Environmental and health impacts of geochemical cycles of persistent toxic substances in food productions systems: Editorial to the special issue for the 8th International Conference on Geochemistry in the Topics \& Sub-tropics (GeoTrop 2017)
}

\author{
Hu-Chun Tao $\cdot$ Zhi-Hong Xu $\cdot$ Jorg Rinklebe $\cdot$ Xia Huo
}

Published online: 31 January 2019

(C) Springer Nature B.V. 2019

The 8th International Conference on Geochemistry in the Topics \& Sub-tropics (GeoTrop 2017): Ecotoxicology of persistent toxic substances in food production was held during 9-12 December 2017 at the Peking University Shenzhen Graduate School in Shenzhen, China. The conference was organized due to the urgent needs to investigate the persistent evidence, environmental behavior and ecotoxicological effects of toxic substances of the food production systems which became a certain issue due to the rapid

\section{H.-C. Tao $(\bowtie)$}

Key Laboratory for Heavy Metal Pollution Control and Reutilization, School of Environment and Energy, Peking University Shenzhen Graduate School, 518055 Shenzhen, Guangdong, China

e-mail: taohc@pkusz.edu.cn

\section{Z.-H. Xu}

School of Natural Sciences, Griffith University, 170

Kessels Road, Nathan, QLD 4111, Australia

\section{J. Rinklebe}

Department D, Soil- and Groundwater-Management, University of Wuppertal, Pauluskirchstraße 7,

42285 Wuppertal, Germany

\section{Huo}

Laboratory of Environmental Medicine and Developmental Toxicology, Guangdong Key Laboratory of Environmental Pollution and Health, School of Environment, Jinan University, 510632 Guangzhou, Guangdong, China development of agricultural/aquacultural industries and growing concerns for public food safety. In Southeast Asia and especially South China (including Hong Kong), frequent occurrence of persistent toxic substances (PTSs) and their implication to health risks in humans have been reported in river/marine water and sediments (e.g. freshwater fish ponds and marine fish cages), farm soils (e.g. paddy soils), and garden soils (e.g. horticulture) and adjacent ecosystems (Lam et al. 2016; Liang et al. 2011; Tao et al. 2016; Xiong et al. 2016). The contamination levels of PTSs in these environmental media are crucial to the quality of fishery, aquatic and agricultural products, posing direct influences on food security. Therefore, there has been a special emphasis on environmental and health impacts of PTSs on food production systems in this region. The GeoTrop 2017 was co-organized by Peking -University Shenzhen Graduate School (China), Shenzhen Center for Disease Control and Prevention (China), Zhejiang A\&F University (China), Jinan University (China), The Education University of Hong Kong, Hong Kong Polytechnic University, Hong Kong Baptist University and Korea University. The 1st Conference of this series was held in Kingston, Jamaica, 1994. The 2nd and the 3rd Conferences were held in Kula Lumpur, Malaysia and in Hong Kong, 1997 and 1999, with the 4th Conference in Townsville, Australia, 2001. The 5th and 6th Conferences were hosted by the Chinese Academy of Sciences in Haikou and Xiamen (China), 2004 and 
2010, respectively. The 7th Conference was held in Bangkok, Thailand, 2012. Herein, the GeoTrop 2017 was co-chaired by Professor Huchun Tao from Peking University Shenzhen Graduate School, Professor Yong Sik Ok from Korea University, Professor Cehui Mo from Jinan University, and Professor Shengchun $\mathrm{Wu}$ from Zhejiang A\&F University. The honorary chairman Professor Ming-Hung Wong was from The Education University of Hong Kong.

This special issue (SI) of Journal of Environmental Geochemistry and Health includes 21 papers presented at the GeoTrop 2017. The research topics of these papers cover the characteristics, behaviors and environmental impacts of both organic and inorganic PTSs, as well as biological elements in either natural or constructed ecosystems. Various scales of investigations were conducted in different ecosystems of South China, India and Malaysia, where rapid population growth brings up an issue of safe and quality food production. All papers are valuable sources of updated and comprehensive information to work out management rules, regulations and policies with regard to PTSs in the rapidly developing Asian region.

The heavy metal (HM) contamination of food, e.g. cadmium-containing rice being planted in polluted soil, has long been a pressing concern in China (Kong 2014) and other Asian countries (Zarcinas et al. 2004). In this SI, 13 papers are presented on the distribution, speciation (bio)-accumulation and toxicological assessment of heavy metals in water/wastewater, sediments and soils of mangrove forests, mining areas and estuarine ecosystems. These ecosystems play key roles in determining the possible composition of agricultural/aquacultural products, forming the basis of every food web (Tóth et al. 2016). Mangrove forests often support abundant fish/shellfish fauna (Nanjo et al. 2014) and herbaceous flora (Walters et al. 2008), being productive of food and medicine for human beings. Meanwhile, a large number of HMs is prone to be retained by adsorption onto fine particles and/or complexation with organic ligands in the mangrove sediments (Niu et al. 2018). In this SI, Li's and Bakshi's groups evaluate the ecotoxicological risks of lead, mercury, copper and zinc to mangroves in South China and India (Bakshi et al. 2018; Shen et al. 2018). As potential sinks or buffers to alleviate toxicity, mangrove plants exhibit a high tolerance to HM pollution, thus preventing them from entering larger aquatic ecosystems. But excessively accumulated
HMs in sediments will inevitably cause multiple (e.g. oxidative and osmotic) stresses on plants, resulting in inhibited photosynthesis, delayed growth and even increased mortality. An altered mineral and trace elemental contents can also be found in medicinal or edible mangrove plants that take up HMs from the polluted habitat sediments. Similar transfer/uptake pathways of cadmium (Hu et al. 2016) and arsenic (Williams et al. 2009) from soil to food crops have been evidenced in China, posing a serious challenge to human health. As a countermeasures against HM pollution, Zhang et al. (2018b) report that biochar can reduce cadmium accumulation in rice grains, which is applicable to paddy soil remediation to safeguard public food health. And Zhang et al. (2018a) develop an electrochemically active bacteria-based sensor for copper toxicity monitoring to early alarm the public in water quality management.

The organic PTSs are a class of chemicals that are ubiquitous in various environmental matrices, making them a global problem of ecosystem damage and human health threat. In total, there are 7 papers in this SI focusing on persistent organic pollutants (POPs), pharmaceutical and personal care products (PPCPs), crude oil and micro-plastics in atmosphere, hydrosphere and biosphere. All of these PTSs are currently regarded as hot-topics with unique and hazardous characteristics. In the air, a wide range of POPs can migrate over long distance at the risk of triggering pathologic changes in human bodies (Roscales et al. 2013). Specifically, Qin et al. (2018) assess the association between 4 atmospheric POPs of carcinogens and human body burden, indicating that children are vulnerable to POPs via respiratory exposure instead of dietary intake. Polycyclic aromatic hydrocarbons (PAHs), a mixture of genotoxic POPs with high lipophilicity to be easily absorbed into human respiratory systems, are also studied as risk factors to raise public's concern on the deterioration of air quality (Wang et al. 2018). In source water, Fu et al. (2018) investigate the occurrence and removal of 29 PPCPs from two typical drinking water treatment plants in China. Effective management policies and remediation techniques are thence proposed to improve the purification process of drinking water. In surface water, Omar et al. (2018) profile the concentrations of 7 pharmaceutically active compounds in a tropical estuarine ecosystem of Malaysia. In-depth knowledge on the baseline levels and 
predicted concentrations of pharmaceutical pollutants are brought to light for future comparative studies within estuarine and coastal ecosystems. In biota, organic PTSs are bio-accumulative in fatty tissues, causing severe damages to living organisms as they move up the food chain (Schafer and Kegley 2002). In crude oil-contaminated seawater, many PHAs are ranked among the most toxic components (Zeng et al. 2015). Phenanthrene (PHE), one of the U.S. Environmental Protection Agency priority PAHs, is found to have a relatively high concentration in crude oil-water solutions (Sun et al. 2018). At quite low exposures, the dissolved PHE is supposed to be easily and rapidly absorbed by marine fish, inducing disorders in lipid metabolism and other developmental abnormalities (Sun et al. 2011). A synergic effect of oil spill pollution and ocean acidification has also been spotted in this SI, further reducing the individual survival of marine fish species as food supplies. On soils from the Yangtze River Delta Region of China, a higher adsorptive capacity of PHE is noted under acidic conditions than near neutral pH (Ping and Luo 2018). In addition, Li et al. (2018) provide an overview of the microRNAs as markers for environmental carcinogenesis. All studies in this SI suggest that both PTS properties and environmental parameters should be considered collaboratively for implementing effective schemes for safe and qualified food production.

For all the above-mentioned reasons, it is of great interest to evaluate the ecotoxicological impacts of PTSs in aquatic, atmospheric and soil environments. Of all PTS contaminants discussed in this SI, HMs, POPs and PPCPs receive particular attention with emphasis on their environmental behaviors closely related to various food production processes. It is envisaged that the valuable information gathered in the Geotrop 2017 will guide "Good Agriculture/ Aquaculture Practices" to secure public health in the Asian region.

\section{References}

Bakshi, M., Ghosh, S., Ram, S., Sudarshan, M., Chakraborty, A., Biswas, J. K., et al. (2018). Sediment quality, elemental bioaccumulation and antimicrobial properties of mangroves of Indian Sundarban. Environmental Geochemistry and Health, 1-22.
Fu, W., Fu, J., Li, X., Li, B., \& Wang, X. (2018). Occurrence and fate of PPCPs in typical drinking water treatment plants in China. Environmental Geochemistry and Health, 1-11.

$\mathrm{Hu}$, Y., Cheng, H., \& Tao, S. (2016). The challenges and solutions for cadmium-contaminated rice in China: A critical review. Environment International, 92, 515-532.

Kong, X. (2014). China must protect high-quality arable land. Nature, 506(7486), 7.

Lam, J. C., Lyu, J., Kwok, K. Y., \& Lam, P. K. (2016). Perfluoroalkyl substances (PFASs) in marine mammals from the South China Sea and their temporal changes 2002-2014: Concern for alternatives of PFOS? Environmental Science and Technology, 50(13), 6728-6736.

Li, M., Huo, X., Davuljigari, C. B., Dai, Q., \& Xu, X. (2018). MicroRNAs and their role in environmental chemical carcinogenesis. Environmental Geochemistry and Health, $1-23$.

Liang, P., Shao, D.-D., Wu, S.-C., Shi, J.-B., Sun, X.-L., Wu, F.Y., et al. (2011). The influence of mariculture on mercury distribution in sediments and fish around Hong Kong and adjacent mainland China waters. Chemosphere, 82(7), 1038-1043.

Nanjo, K., Kohno, H., Nakamura, Y., Horinouchi, M., \& Sano, M. (2014). Differences in fish assemblage structure between vegetated and unvegetated microhabitats in relation to food abundance patterns in a mangrove creek. Fisheries Science, 80(1), 21-41.

Niu, Z., Cao, Y., Zhao, W., \& Li, R. (2018). Distribution and assessment of mercury $(\mathrm{Hg})$ in surface sediments of Futian mangrove forest, China. Environmental Geochemistry and Health, 1-10.

Omar, T. F. T., Aris, A. Z., Yusoff, F. M., \& Mustafa, S. (2018). Risk assessment of pharmaceutically active compounds (PhACs) in the Klang River estuary, Malaysia. Environmental Geochemistry and Health, 1-13.

Ping, L., \& Luo, Y. (2018). Phenanthrene adsorption on soils from the Yangtze River Delta region under different $\mathrm{pH}$ and temperature conditions. Environmental Geochemistry and Health, 1-8.

Qin, Q., Xu, X., Dai, Q., Ye, K., Wang, C., \& Huo, X. (2018). Air pollution and body burden of persistent organic pollutants at an electronic waste recycling area of China. Environmental Geochemistry and Health, 1-31.

Roscales, J., Muñoz-Arranz, J., Morales, L., Abad Holgado, E., \& Jiménez, B. (2013). PCDD/Fs, dioxin-like PCBs and PBDEs in air: Preliminary results of the Spanish monitoring program on POPs under the Stockholm convention after 4 years monitoring.

Schafer, K. S., \& Kegley, S. E. (2002). Persistent toxic chemicals in the US food supply. Journal of Epidemiology and Community Health, 56(11), 813-817.

Shen, X., Li, R., Chai, M., Cheng, S., Niu, Z., \& Qiu, G. Y. (2018). Interactive effects of single, binary and trinary trace metals (lead, zinc and copper) on the physiological responses of Kandelia obovata seedlings. Environmental Geochemistry and Health, 1-14.

Sun, L., Ruan, J., Lu, M., Chen, M., Dai, Z., \& Zuo, Z. (2018). Combined effects of ocean acidification and crude oil pollution on tissue damage and lipid metabolism in embryo-larval development of marine medaka (Oryzias 
melastigma). Environmental Geochemistry and Health, $1-14$.

Sun, L., Zuo, Z., Luo, H., Chen, M., Zhong, Y., Chen, Y., et al. (2011). Chronic exposure to phenanthrene influences the spermatogenesis of male Sebastiscus marmoratus: U-shaped effects and the reason for them. Environmental Science and Technology, 45(23), 10212-10218.

Tao, H., Zhao, K., Ding, W., Li, J., Liang, P., Wu, S., et al. (2016). The level of mercury contamination in mariculture sites at the estuary of Pearl River and the potential health risk. Environmental Pollution, 219, 829-836.

Tóth, G., Hermann, T., Da Silva, M. R., \& Montanarella, L. (2016). Heavy metals in agricultural soils of the European Union with implications for food safety. Environment International, 88, 299-309. https://doi.org/10.1016/j. envint.2015.12.017.

Walters, B. B., Rönnbäck, P., Kovacs, J. M., Crona, B., Hussain, S. A., Badola, R., et al. (2008). Ethnobiology, socio-economics and management of mangrove forests: A review. Aquatic Botany, 89(2), 220-236.

Wang, Q., Xu, X., Cong, X., Zeng, Z., Xu, L., \& Huo, X. (2018). Interactions between polycyclic aromatic hydrocarbons and epoxide hydrolase 1 play roles in asthma. Environmental Geochemistry and Health, 1-20.

Williams, P. N., Lei, M., Sun, G., Huang, Q., Lu, Y., Deacon, C., et al. (2009). Occurrence and partitioning of cadmium, arsenic and lead in mine impacted paddy rice: Hunan,
China. Environmental Science \& Technology, 43(3), 637-642.

Xiong, J., Li, G., An, T., Zhang, C., \& Wei, C. (2016). Emission patterns and risk assessment of polybrominated diphenyl ethers and bromophenols in water and sediments from the Beijiang River, South China. Environmental Pollution, 219, 596-603.

Zarcinas, B. A., Ishak, C. F., McLaughlin, M. J., \& Cozens, G. (2004). Heavy metals in soils and crops in Southeast Asia. Environmental Geochemistry and Health, 26(4), 343-357.

Zeng, X., Chen, X., \& Zhuang, J. (2015). The positive relationship between ocean acidification and pollution. Marine Pollution Bulletin, 91(1), 14-21.

Zhang, L., Li, S. F. Y., \& Tao, H. (2018a). Toxicity assessment of copper by electrochemically active bacteria in wastewater. Environmental Geochemistry and Health, 1-11.

Zhang, M., Shan, S., Chen, Y., Wang, F., Yang, D., Ren, J., et al. (2018b). Biochar reduces cadmium accumulation in rice grains in a tungsten mining area-field experiment: effects of biochar type and dosage, rice variety, and pollution level. Environmental Geochemistry and Health, 1-10.

Publisher's Note Springer Nature remains neutral with regard to jurisdictional claims in published maps and institutional affiliations. 